\title{
Banho humanizado em recém-nascidos prematuros de baixo peso em uma enfermaria canguru*
}

\section{Bath humanized in premature newborns with low weight in a kangaroo infirmary}

\author{
Julie Souza Soares de Medeiros ${ }^{1}$, Maria de Fátima \\ Pessoa Tenório Mascarenhas ${ }^{2}$
}

\begin{abstract}
MEDEIROS, J. S.; MASCARENHAS, M. F. P. T. Banho humanizado em recém-nascidos prematuros de baixo peso em uma enfermaria canguru. Rev. Ter. Ocup. Univ. São Paulo, v. 21, n. 1, p. 51-60, jan./abr. 2010.

RESUMO: O banho é considerado uma prática com alto nível de manipulação que gera desorganização e estresse ao recém-nascido $(\mathrm{RN})$ de risco, pois este apresenta comportamentos que estão em amadurecimento. Objetivou-se investigar a adequação do banho humanizado nos RN prematuros e de baixo peso internados em uma enfermaria canguru, identificando suas contribuições para a resposta adaptativa ao ambiente. Trata-se de um estudo observacional de corte transversal desenvolvido com 35 RN internados numa maternidade em Maceió-AL, de abril a junho de 2009, utilizando a observação direta junto ao recurso da filmagem. Foi observada a presença de sinais de aproximação em todos os comportamentos, constatando que o banho humanizado favorece a auto-organização destes RN.
\end{abstract}

DESCRITORES: Prematuro. Recém-nascido de baixo peso. Humanização da assistência. Estudos transversais.

* Estudo apresentado parcialmente sob forma oral no XI Congresso Brasileiro de Terapia Ocupacional, em 13 de outubro de 2009 na cidade de Fortaleza, Ceará, Brasil.

Estudo apresentado à Universidade Estadual de Ciências da Saúde de Alagoas, na Faculdade de Terapia Ocupacional, como Trabalho de Integralização Curricular, sendo parte integrante dos requisitos para obtenção do grau de Bacharel em Terapia Ocupacional, em 09 dezembro de 2009.

Instituições envolvidas: Maternidade Escola Santa Mônica e Universidade Estadual de Ciências da Saúde de Alagoas.

1. Discente de Terapia Ocupacional da Universidade Estadual de Ciências da Saúde de Alagoas (Uncisal), email: julie.ssm@gmail.com

2. Terapeuta Ocupacional. Especialista em Estimulação Precoce pela Escola de Ciências Médicas de Alagoas (ECMAL). Professora Auxiliar da Faculdade de Terapia Ocupacional da Universidade Estadual de Ciências da Saúde de Alagoas. Gerente do serviço de Terapia Ocupacional da Maternidade Escola Santa Mônica - Maceió (AL), email: fatimascarenhas@hotmail.com

Endereço para correspondência: Avenida Litorânea, 173, Jacarecica, Maceió, Alagoas, Brasil. CEP: 57039-080. 


\section{INTRODUÇÃO}

$\mathrm{C}$ om os avanços tecnológicos em neonatologia e a introdução de novas técnicas de assistência ao Recém-Nascido (RN), principalmente os prematuros e de baixo peso, houve aumento na sobrevida (RIBEIRO, 2005), como também aumentou a incidência de sequelas graves, alterando significamente a qualidade de vida desses $\mathrm{RN}$ de grande risco.

A Organização Mundial de Saúde define prematuro toda criança nascida viva antes de 37 semanas de gestação (CUNHA, 2002; LEONE, 2002; MURAHOVSCHI, 2006; REGO, 2004). Quanto ao peso de nascimento, o RN poderá ser considerado de baixo peso, quando o peso de nascimento for inferior a $2500 \mathrm{~g}$, independente da idade gestacional (COLE, 2003; MURAHOVSCHI, 2006; REGO, 2004). Os índices mostram que no mundo nascem anualmente 20 milhões de bebês prematuros e com baixo peso e sua incidência varia entre 7 e $15 \%$ do total dos nascimentos vivos (BRASIL, 2009; CARVALHO, 2001; MURAHOVSCHI, 2006).

O Brasil vem trabalhando com a visão de um novo paradigma, o da atenção humanizada à criança, à mãe e à família, respeitando-as em suas características e individualidades. Conforme descrito pelo Ministério da Saúde (BRASIL, 2009, p. 11, 16-7):

em 1979 foi iniciado na Colômbia o Método Mãe-Canguru (MMC), método de assistência humanizada prestada ao $\mathrm{RN}$, notadamente os de baixo peso, que após estabilização inicial, o contato pele a pele entre a mãe e o bebê é iniciado de forma precoce e crescente, por livre escolha da família e pelo tempo que ambos entenderem prazeroso e suficiente. As vantagens deste método são: favorecer o vínculo mãefilho, melhorar a qualidade do desenvolvimento neurocomportamental e psico-afetivo do RN, estimular o aleitamento materno, promover controle térmico adequado, favorecer a estimulação sensorial adequada do $\mathrm{RN}$, reduzir o risco hospitalar, o estresse e a dor dos RN, além de propiciar um melhor relacionamento entre a família e a equipe de saúde, possibilitando maior competência e confiança dos pais no manuseio do seu filho de baixo peso.

O período neonatal torna-se uma época altamente vulnerável para o neonato, que está completando muitos dos ajustes fisiológicos essenciais à existência extrauterina, visto que este apresenta imaturidade morfológica e funcional (RIBEIRO, 2005; STOLL, 2002). Pode-se afirmar que o desenvolvimento é um processo contínuo de adaptação entre o sistema interno, que compreende a organização fisiológica e comportamental do bebê, e o sistema externo, incluindo vários aspectos do ambiente físico e daqueles que cuidam do bebê (ALS, 1986 apud MEYERHOF, 1996, p. 27).
O modelo síncrono-ativo do desenvolvimento delineia caminhos para observar o funcionamento cerebral, via comportamento do bebê. De acordo com esta teoria, os cinco subsistemas de desenvolvimento (autônomo, motor, de organização dos estados, de atenção e de autorregulação) podem ser observadas a olho nu, o que permite a identificação do limiar daquele bebê em relação ao estresse, e ao aumento da capacidade de autorregulação e de autodiferenciação entre os subsistemas (ALS, 1986 apud MEYERHOF, 1996, p. 29).

Brazelton (1982) verificou que há uma relação entre o controle dos estados de consciência do neonato e a capacidade de autorregulação do bebê. Portanto, desde o seu nascimento, o bebê aprende a manipular reações psicofisiológicas internas e a controlar uma hiperestimulação externa (BRAZELTON, 1982 apud MEYERHOF, 1996, p. 42).

Desse modo, os comportamentos são observados a partir de sinais expressos pelo bebê, podendo ser de aproximação (positivo) indicando que o bebê está recebendo uma quantidade de estimulação e de interação adequada ou de estresse (negativo), que indicam que o bebê está muito estressado e os estímulos devem ser gradativamente retirados. Ministério da Saúde (BRASIL, 2009, p. 66-7) define:

sinais de aproximação: frequência cardíaca e respiratória regular, cor de pele e funções digestivas estáveis, mantém tônus muscular, leva/mantém mão na face ou na boca, busca sucção e preensão, sono profundo, estado de alerta inativo acalmando-se com facilidade, dirige o rosto, eleva sobrancelhas, franze testa e lábios; e sinais de estresse como: palidez, moteamento, cianose perioral, bradicardia, respiração irregular, apnéia, aumento ou diminuição da frequência cardíaca, movimentos peristálticos, aumentos do resíduo gástrico, vômitos, engasgos, soluços, tremores, susto, flacidez e hipertonia motora, sono difuso, estado de alerta com choramingo ou irritabilidade e choro.

Como o cérebro do RN prematuro é um órgão chave que rege e atua sobre todos os aspectos do seu desenvolvimento, e como o neonato ainda está num estágio de desenvolvimento bastante delicado, ele tem dificuldade de se manter em qualquer um dos estados comportamentais durante um período longo de tempo, dificultando um enfoque seletivo dos elementos do meio ambiente enquanto o seu sistema central regula as funções do corpo automaticamente (MEYERHOF, 1996).

A manipulação do ambiente do pré-termo tem importância capital na prevenção de complicações clínicas. Meyerhof (1994, p. 44) sugere que se deve estruturar o ambiente de tal forma que o bebê consiga uma melhor auto-organização. Portanto, o objetivo das intervenções será tanto no sentido de promover a entrada sensorial, como o 
de proteger o bebê do excesso de estimulação, graduando os estímulos de acordo com o desenvolvimento adaptativo do neonato.

Dentre as manipulações realizadas na rotina hospitalar, o banho é uma atividade de vida diária que visa à limpeza e a proteção do revestimento externo do corpo, estimulando a circulação geral da pele, proporcionando sensação de conforto e bem-estar (CONCEIÇÃO, 2002). Para o Ministério da Saúde (BRASIL, 2002; 2009), este procedimento caracteriza-se por um nível alto de manipulação do bebê, o qual podem produzir diversas reações no RN. Desta forma, o banho deverá ser realizado levando em consideração o estado e as pistas fisiológicas e/ou comportamentais que o bebê apresenta.

Assim, foi preconizado no MMC o procedimento de banho humanizado, como sendo o mais indicado na assistência ao RN de baixo peso, no qual o RN é imerso em água morna até o pescoço, sem exposição à corrente de ar, e com contenção do padrão flexor através do enrolamento com toalha-fralda, de modo a evitar o estresse, a desorganização motora e o gasto energético e proporcionar relaxamento e prazer ao RN submetido (BRASIL, 2002, 2009).

Portanto, cientes da importância da adaptação do banho para o desenvolvimento do bebê, o presente estudo visou investigar a adequação do banho humanizado em recém-nascidos prematuros e de baixo peso internados em uma enfermaria canguru, identificando suas contribuições para a resposta adaptativa ao ambiente.

\section{PROCEDIMENTOS METODOLÓGICOS}

Trata-se de um estudo observacional, descritivo com corte transversal, realizado entre os meses de abril e junho de 2009, na enfermaria canguru da Maternidade Escola Santa Mônica, Maceió, Alagoas. Esta instituição é uma maternidade pública de referência em atendimentos obstétricos e neonatais de alta complexidade e no período de coleta de dados era a única maternidade do Estado participante da estratégia Método Mãe-Canguru do Ministério da Saúde.

O tamanho da amostra foi definido em 35 indivíduos, considerando o universo $(\mathrm{N})$ de 47 , número correspondente a proporção de indivíduos atendidos em igual período (abril, maio e junho) no ano antecedente na mesma enfermaria canguru, a proporção de $\mathrm{RN}$ que responderam satisfatoriamente ao banho de $90 \%$, erro tolerável de $5 \%$, e nível de significância $(\alpha)$ de $5 \%$, sendo utilizada uma calculadora eletrônica disponível na Internet (http://lia. uncisal.edu.br/ensino/pos_grad2_mat2.html).

Deste modo, a amostra foi composta por $35 \mathrm{RN}$ com idade gestacional entre 28 semanas e 36 semanas e 6 dias e peso ao nascimento entre $1000 \mathrm{~g}$ e $2499 \mathrm{~g}$, de ambos os sexos, não portadores de disfunções respiratórias, cardíacas, neurológicas e/ou genéticas. Os bebês participantes do estudo não estavam: em abstinência alimentar, com menos de 30 minutos ou mais de 1 hora e 30 minutos da última dieta, submetidos à terapia medicamentosa depressora do Sistema Nervoso Central, e não receberam massagem antes e após o banho.

Para a fase de coleta de dados, inicialmente foram selecionados os sujeitos da pesquisa. Esta fase consistiu em fazer o levantamento dos dados clínicos e sociais presentes no prontuário médico, para o preenchimento de um questionário sóciodemográfico produzido pelas pesquisadoras. De posse desse questionário, foi feito um contato com as genitoras responsáveis pelos $\mathrm{RN}$ e aquelas que consentiram em participar do pesquisa forneceram sua autorização mediante a assinatura do termo de Consentimento Livre e Esclarecido (TCLE). Assim, de posse a estes dados, foi utilizada uma amostra probabilística, amostra aleatória simples, para seleção dos RN, onde os mesmos foram elegidos por meio de um sorteio através de uma numeração aleatória.

A etapa de coleta de dados constituiu de considerações acerca do banho, sendo ele realizado às 07 horas nos meses de abril e junho e às 13 horas no mês de maio, em um único momento para todos os RN. Nesta etapa foi aplicada a técnica de observação direta dos $\mathrm{RN}$ antes, durante e após o procedimento. Paralelamente, durante o processo foi feito o preenchimento da ficha de observação dos sinais dos subsistemas, desenvolvida pelas pesquisadoras de acordo com a Teoria Síncrono Ativa do Desenvolvimento desenvolvida por ALS (1986), a qual foi elegida como alicerce teóricometodológico e que possui como premissa a compreensão do funcionamento nos subsistemas autonômico, motor, dos estados comportamentais, de atenção/interação e regulador, em busca do estado de equilíbrio. Tal teoria foi projetada para documentar a complexidade e sensibilidade do RN prematuro e de baixo peso (BRASIL, 2009). O banho foi realizado seguido do protocolo de execução das etapas do banho humanizado descrito pelo manual de atenção humanizada RN de baixo peso do Método Mãe Canguru do Ministério da Saúde (2002, 2009) (BRASIL, 2002; 2009). Antes e após o banho foi utilizado ainda, estetoscópio e cronômetro como dispositivos para verificar a frequência cardíaca dos RN, constatando os batimentos durante um minuto (batimentos por minuto - bpm), considerando a frequência regular de 80 à 160 bpm (NICOLAU, 2008). Para a verificação da freqüência respiratória, foi realizada a observação das excursões torácicas do bebê durante um minuto completo (MILTERSTEINER, 2003). 
Durante o banho realizado pela equipe de enfermagem, foi utilizado o recurso da filmagem através de uma câmera fotográfica (Sony W50) como instrumento de observação para análise precisa dos comportamentos apresentados pelos RN.

$\mathrm{Na}$ observação direta, a dupla de observadores permaneceu à beira do leito e da banheira, enquanto transcorria todas as fases do banho (preparação, execução e conclusão) no ambiente da enfermaria canguru, mantendo uma distância aproximada de $1 \mathrm{~m}$ e $50 \mathrm{~cm}$ da banheira, para que não houvesse interferências no comportamento do bebê durante os procedimentos. Para a filmagem, que ocorreu durante o banho, a dupla de observadores permaneceu numa distância aproximada de $1 \mathrm{~m} 50 \mathrm{~cm}$ da banheira, registrando as interações do bebê durante o procedimento. Os dados coletados na filmagem foram registrados na ficha de observação e submetidos a análise posterior pela dupla de pesquisadoras.

Foram observadas as respostas fisiológicas e comportamentais emitidas pelo RN, como alteração nos padrões de sono, de choro e de irritação, mudanças na coloração da pele e alterações nos sistemas cardiorrespiratório, visceral, motor e de atenção e interação. Os dados coletados foram analisados e armazenados em uma planilha eletrônica de dados do Microsoft Office Excel 2007 for Windows XP, onde receberam tratamentos estatísticos descritivo, sendo apresentados na forma de gráficos.

A pesquisa foi desenvolvida após aprovação da Gerência Docente Assistencial da instituição onde foi realizada a pesquisa, conforme termo de autorização $\mathrm{n}^{\circ} 22 / 2008$, e do Comitê de Ética em Pesquisa da Universidade Estadual de Ciências da Saúde de Alagoas, conforme protocolo ${ }^{\circ}$ 1056, sendo realizada de acordo com a Resolução n 196/96 do Conselho Nacional de Saúde, referente a pesquisas com seres humanos.

\section{RESULTADOS}

A população estudada foi composta por $35 \mathrm{RN}$ prematuros e de baixo peso, sendo $19(54,3 \%)$ do sexo masculino e $16(45,7 \%)$ do sexo feminino. A idade gestacional variou entre 28 e 34,5 semanas, tendo como média 32 semanas e 06 dias, e o peso ao nascer permaneceu entre $1050 \mathrm{~g}$ e $2125 \mathrm{~g}$, tendo $1.558 \mathrm{~g}$ como média. Os dados sobre as características gerais dos RN estão apresentados na Tabela 1.

Tabela 1 - Características gerais dos recém-nascidos prematuros de baixo peso internados em uma enfermaria canguru que participaram do estudo. Maceió (AL), 2009

\begin{tabular}{|c|c|c|}
\hline Características Gerais & População (n=35) & Média / Porcentagem (\%) \\
\hline Peso ao nascer & $1050-2125 \mathrm{~g}$ & $\pm 1.558 \mathrm{~g}$ \\
\hline Idade gestacional & $28-34,5 \mathrm{sem}$ & $\pm 32,6 \mathrm{sem}$ \\
\hline \multicolumn{3}{|l|}{ Sexo } \\
\hline Feminino & 16 & $45,7 \%$ \\
\hline Masculino & 19 & $54,3 \%$ \\
\hline \multicolumn{3}{|l|}{ Adequação nutricional } \\
\hline Adequado para idade gestacional & 22 & $62,9 \%$ \\
\hline Pequeno para idade gestacional & 13 & $37,1 \%$ \\
\hline \multicolumn{3}{|l|}{ Tipo de dieta } \\
\hline Seio materno & 06 & $17,2 \%$ \\
\hline Fórmula & 0 & $0 \%$ \\
\hline Complemento (sonda/copo) & 29 & $82,8 \%$ \\
\hline \multicolumn{3}{|l|}{ Quanto tempo foi alimentado } \\
\hline 30 minutos - 1hora & 12 & $34,3 \%$ \\
\hline 1 hora -1 hora e 30 minutos & 23 & $65,7 \%$ \\
\hline
\end{tabular}

Foram observadas as respostas dos RN quanto ao estado comportamental, e aos subsistemas autonômico, motor, e de atenção/interação.

Com relação ao estado comportamental foram observados os estados de sono profundo, sono leve, alerta inativo, alerta ativo (com choramingo, irritabilidade e acalmandose com facilidade) e choro. Antes do banho, 74\% dos RN estavam em alerta inativo e $20 \%$ em sonolência, indicando sinais de aproximação. Durante o banho, houve transição para seis estados comportamentais: $43 \%$ em alerta inativo, 
$17 \%$ em sonolência, $14 \%$ em alerta ativo acalmando-se com facilidade, $11 \%$ em alerta ativo com choramingo, $11 \%$ em choro intenso e $3 \%$ em alerta ativo com irritabilidade. Considerando que os três primeiros estados são sinais de aproximação do RN, houve desta forma, um percentual positivo elevado de $77 \%$ durante o procedimento. Após o banho, $83 \%$ dos RN encontraram-se no estado de alerta inativo, $9 \%$ em alerta ativo acalmando-se com facilidade, $3 \%$ em sonolência, 3\% em sono leve e 3\% em alerta ativo com choramingo, demonstrando que $97 \%$ não apresentaram sinais de estresse, como choro, alerta ativo com choramingo ou irritabilidade (Gráfico 1).

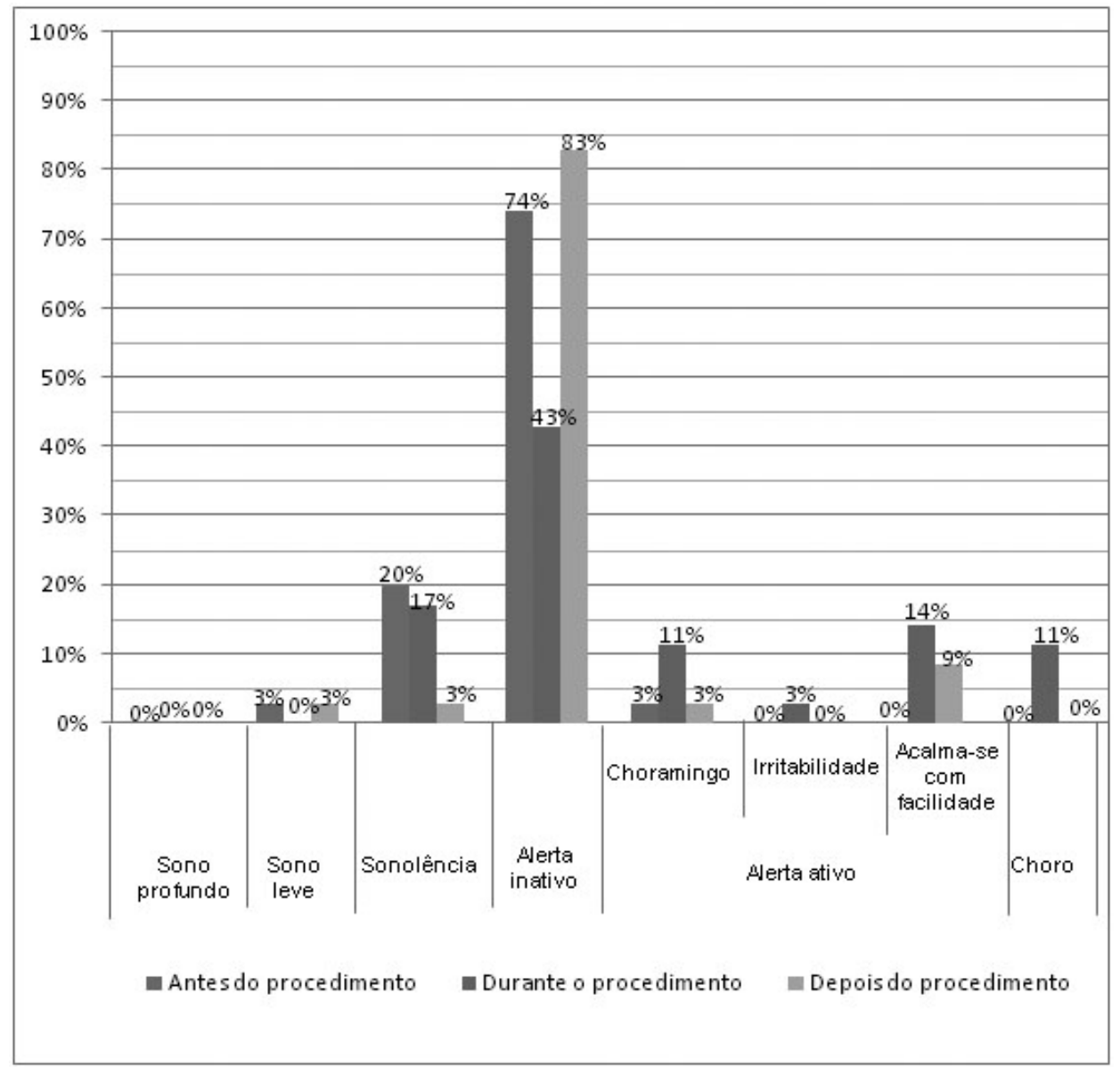

Gráfico 1 - Estados comportamentais encontrados antes, durante e após o banho humanizado em recém-nascidos prematuros de baixo peso internados em uma enfermaria canguru. Maceió (AL), 2009

O Gráfico 2 mostra os percentuais encontrados no subsistema autonômico antes, durante e após o banho, sendo observado a coloração da pele (rosada, palidez, moteamento ou cianose perioral), o sistema cardiorrespiratório (frequência cardíaca, respiração regular ou irregular) e as respostas viscerais (estáveis ou instáveis), sendo a frequência cardíaca verificada somente antes e após o procedimento. Em relação a estes aspectos, não foram observados sinais significativos de estresse antes, durante ou após o procedimento. Desta forma, a coloração da pele predominou rosada antes, durante e após o banho, com $100 \%, 97 \%$ e $100 \%$, respectivamente. No sistema cardiorrespiratório, os índices permaneceram respectivamente em $97 \%, 86 \%$ e $97 \%$ antes, durante e após o banho, tendo em média a frequência cardíaca de 134 bpm e 136 bpm antes e após o procedimento. Com relação aos sinais viscerais, os índices estiveram em $97 \%$ antes e após o banho e $91 \%$ durante o procedimento, onde foi observada em alguns dos RN a presença de soluços e engasgos, demonstrando sinais de estresse. 


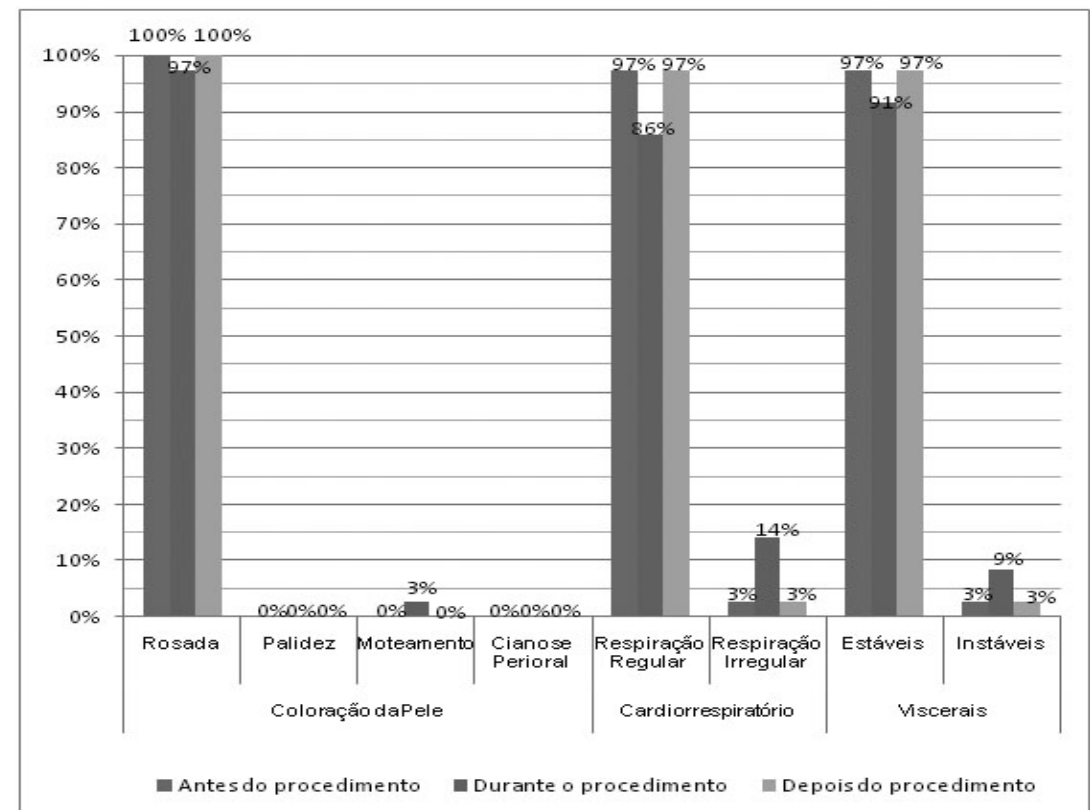

Gráfico 2 - Respostas encontradas no subsistema autonômico antes, durante e após o banho humanizado em recém-nascidos prematuros de baixo peso internados em uma enfermaria canguru. Maceió (AL), 2009

Em relação ao subsistema motor foi observada a predominância do tônus muscular dos RN, se equilibrado, em flacidez ou hipertonia motora não patológica (sentado no ar, saudação ou arqueamento), antes, durante e após o banho. Os resultados mostram que $100 \%$ dos $\mathrm{RN}$ apresentam tônus muscular equilibrado antes e depois do banho e 94\% durante o banho, indicando sinais positivos dos bebês ao procedimento (Gráfico 3).

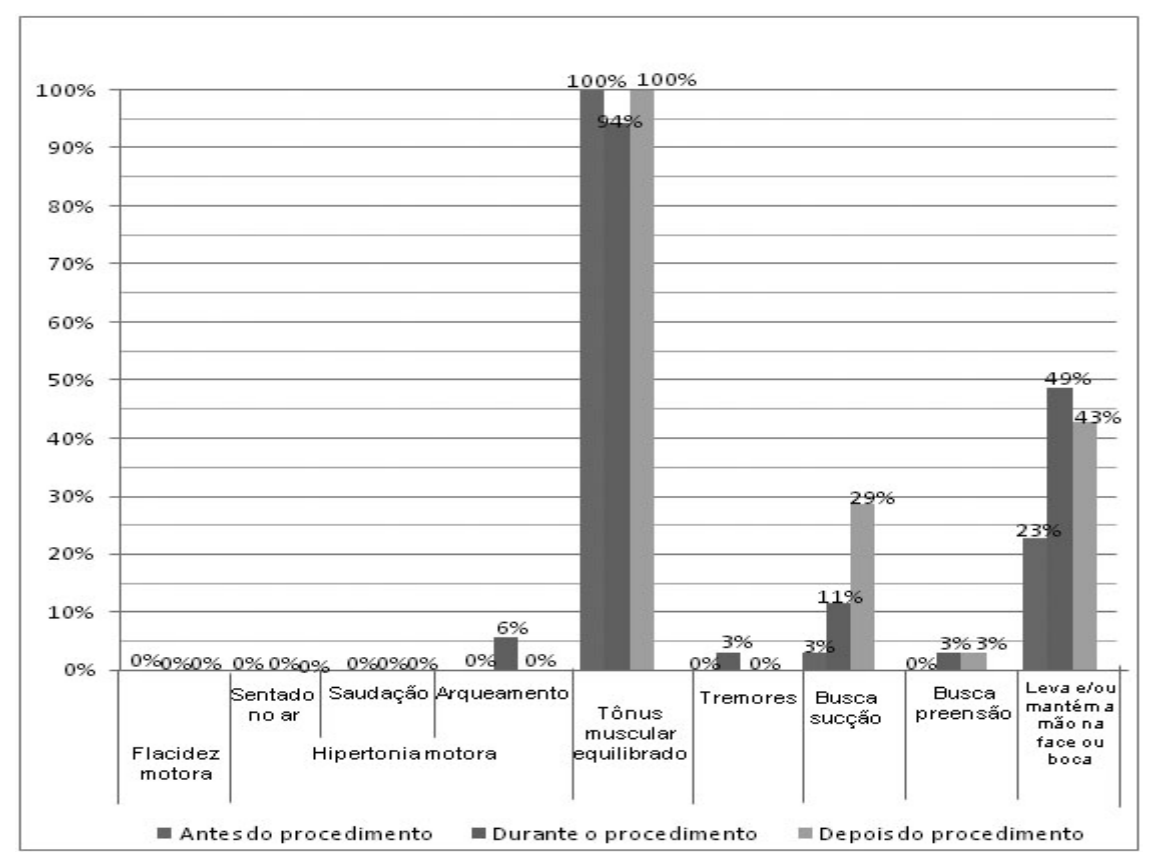

Gráfico 3 - Respostas encontradas no subsistema motor encontradas antes, durante e após o banho humanizado em recém-nascidos prematuros de baixo peso internados em uma enfermaria canguru. Maceió (AL), 2009 
O Gráfico 3 demonstra ainda o aparecimento de sinais motores de aproximação (busca preensão, busca sucção, leva e/ou mantém a mão na face ou na boca) e de estresse (tremores) nos RN (apenas em 3\% dos casos). Observa-se que antes do banho, $3 \%$ dos bebês apresentam busca por sucção e 23\% levam e/ou mantêm a mão na face ou na boca. Durante o banho 3\% apresentam tremores, $11 \%$ busca sucção, $3 \%$ busca preensão e $49 \%$ levam e/ou mantêm a mão na face ou na boca. Após o procedimento, $29 \%$ dos RN apresentam busca por sucção, 3\% busca por preensão e $43 \%$ levam e/ou mantêm a mão na face ou na boca.

No subsistema de atenção/interação foi observado o aparecimento de sinais de aproximação, como elevar as sobrancelhas, dirigir o rosto para o examinador e franzir os lábios ("ooh") em 25\% (antes), $83 \%$ (durante) e 15\% (depois) dos RNs avaliados durante os procedimentos de banho. Antes do banho, 14\% dos RN dirigiram ao rosto do examinador e $11 \%$ franziram os lábios. Durante o procedimento estes números permaneceram em $9 \%$ e $14 \%$, respectivamente, para os aspectos citados antes do banho, enquanto $60 \%$ elevaram sobrancelhas, sendo este sinal bastante evidenciado na postura de decúbito ventral, onde eles apresentam uma maior tentativa de se auto-organizar. Após o banho, 9\% dirigiram o rosto para o examinador, enquanto 6\% franziram os lábios (Gráfico 4).

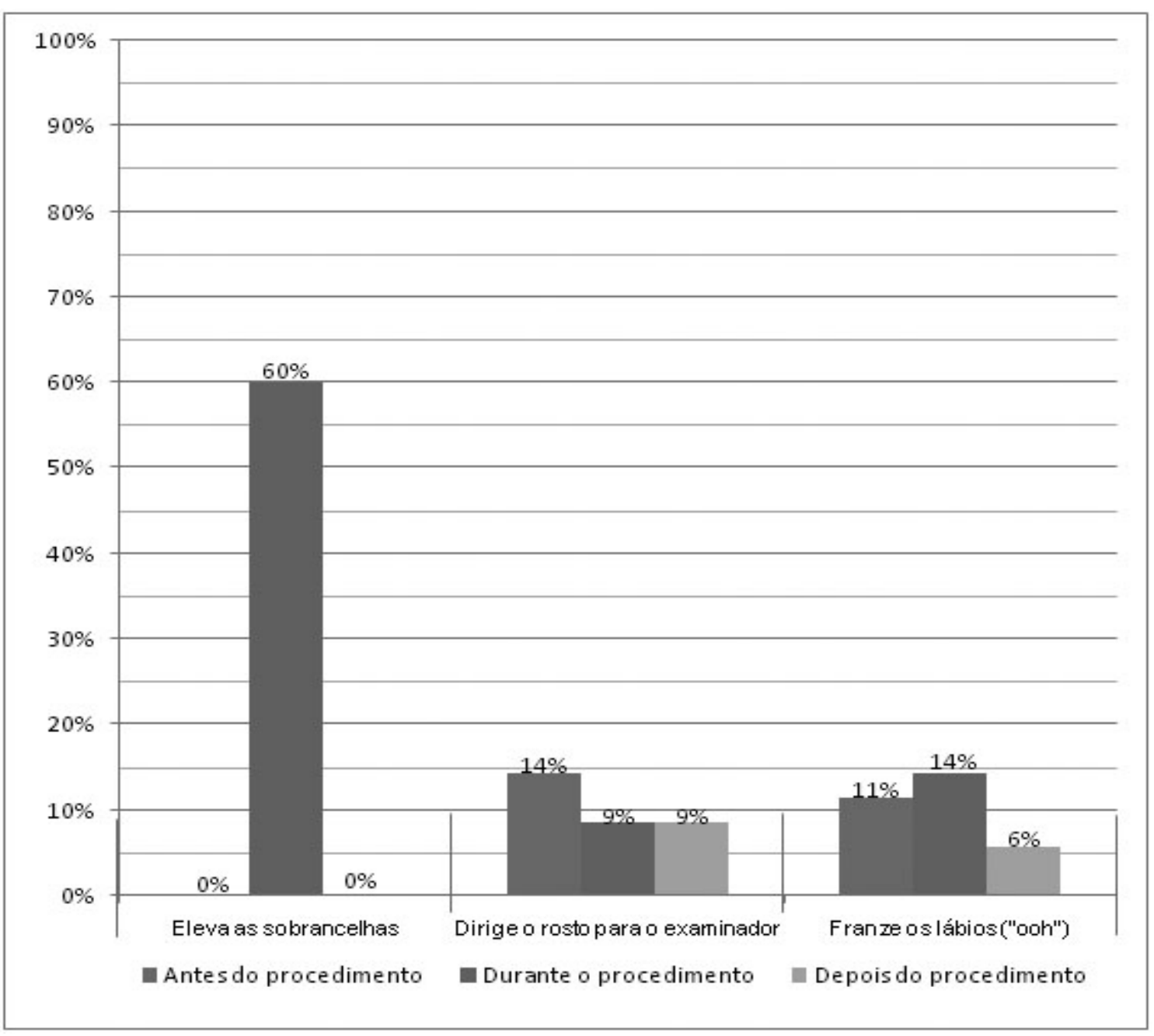

Gráfico 4 - Sinais apresentados no subsistema de atenção/interação antes, durante e após o banho humanizado em recém-nascidos prematuros de baixo peso internados em uma enfermaria canguru. Maceió (AL), 2009 


\section{DISCUSSÃO}

Sabe-se que a forma como o neonato é manuseado durante os cuidados de rotina pode afetar sua estabilidade fisiológica e comportamental (TAMEZ, 2009). Desta forma se o estímulo for apropriado para o neonato em um determinado momento de interação, em nível de complexidade e intensidade relacionado à capacidade do neonato em reagir, o prematuro vai mostrar sinais de calma e interação (TAMEZ, 2009), como podemos evidenciar antes, durante e após o banho, nos estados comportamentais (sono leve, sonolência, alerta inativo e alerta ativo acalmando-se com facilidade), no subsistema autonômico (coloração da pele, respiração, frequência cardíaca e sinais viscerais regulares), motor (tônus equilibrado, busca preensão, busca sucção, leva e/ou mantém a mão na face ou na boca), e de atenção/interação (elevar as sobrancelhas, dirigir o rosto para o examinador e franzir os lábios), onde a maioria dos bebês responderam de forma positiva ao procedimento realizado.

Quando o estímulo for muito complexo, intenso ou em tempo inapropriado, o prematuro vai tentar evitar a aproximação e mostrará sinais de estresse (TAMEZ, 2009), como demonstrado em uma pequena porcentagem dos bebês observados, sendo apresentados estes sinais na forma de choro, alerta inativo com choramingo e irritabilidade, respiração e sinais viscerais irregulares (soluço e engasgo), hipertonia ou flacidez motora e tremores.

Embora o banho seja considerado um procedimento com alto nível de manipulação, a proposta do banho humanizado por imersão induz a minimização dos efeitos deletérios nos sistemas fisiológicos, comportamentais e de interação dos bebês, apresentando sinais de aproximação nos cinco subsistemas estudados, conforme citado anteriormente. Resultados semelhantes a este estudo foram observados por Lund (LUND, 2006 apud TAMEZ, 2009, p. 97), Correia et al. (2004 apud TAMEZ, 2009, p. 98), Henningsson et al. (1981) e Bryanton (2004 apud TAMEZ, 2009 , p. 97), onde foi constatado que o banho realizado por imersão contribui do ponto de vista desenvolvimentista para o bebê, promovendo um balanço comportamental e fisiológico, causando menos perda de calor, não aumentando o índice de infecção, além de proporcionar relaxamento ao neonato.

Com a prática de observação dos sinais emitidos pelos bebês, os cuidadores passam a ser facilitadores do neonato, e os comportamentos de estresse e aproximação poderão ser modelados de acordo com as intervenções, para que o bebê não seja levado à exaustão e ao gasto energético por meio dos muitos cuidados a ele direcionados pela equipe de saúde, refletindo negativamente em termos fisiológicos no desenvolvimento do Sistema Nervoso Central (BRASIL, 2002).

Associado a observação, podemos verificar que a imersão em água morna juntamente com a contenção do padrão flexor reduz a desorganização neuropsicomotora, promovendo melhor ajuste do $\mathrm{RN}$ ao meio, e tornando mínimo o estresse sobre os bebês, proporcionando relaxamento e atenção individualizada, respeitando as peculiaridades dos RN, para que ele seja capaz de interagir com o ambiente tolerando a intervenção sem que esta interfira nas suas funções fisiológicas, comportamentais e interacionais.

Conforme encontrado na literatura (BRYANTON, 2004 apud TAMEZ, 2009, p. 97; CORREIA et al., 2004 apud TAMEZ, 2009, p. 98; HENNINGSSON et al., 1981; LUND, 2006 apud TAMEZ, 2009, p. 97), e corroborando com os resultados encontrados neste estudo, o banho humanizado demonstra ser um procedimento que gera autoorganização nos $\mathrm{RN}$ prematuros e de baixo peso, pois propicia a homeostase promovendo harmonia e inter-relação entre os subsistemas, diminuído o desgaste de energia e favorecendo o desenvolvimento sadio destes $\mathrm{RN}$.

\section{CONCLUSÃO}

Considerando o RN prematuro e de baixo peso como um ser que se encontra em desenvolvimento, apresentando imaturidade morfológica e fisiológica, este necessita de um cuidado individualizado, onde devem ser levadas em consideração as suas necessidades e particularidades, respeitando desta forma, a sua condição diferenciada de desenvolvimento.

Acreditamos que o manuseio adequado será aquele em que o cuidador necessita prestar atenção nos comportamentos autorregulatórios ou de organização e nos comportamentos de estresse, promovendo assim uma adequação dos estímulos e intervenções oferecidos, facilitando desta maneira, a transição ou homeostase com menos gasto energético, colaborando para um desenvolvimento equilibrado destes RN.

Desta forma, sugere-se que o banho humanizado seja o mais adequado para estes $\mathrm{RN}$, pois proporciona melhor resposta adaptativa ao ambiente, promovendo organização dos sistemas comportamentais, motores, fisiológicos e de interação ao meio, contribuindo beneficamente para o desenvolvimento sadio dos mesmos. 
MEDEIROS, J. S., MASCARENHAS, M. F. P. T. Bath humanized in premature newborns with low weight in a kangaroo infirmary. Rev. Ter. Ocup. Univ. São Paulo, v. 21, n. 1, p. 51-60, jan./ abr. 2010 .

\begin{abstract}
The bath is considered a practice with high level of manipulation that desorganizes and distresses the risk newborn (NB) infant, once the child exhibits behaviors that are still maturing. It was aimed to investigate the adequacy of the humanized bath in low weight premature infants samitted in a kangaroo nursery, identifying its contributions to the adaptive response related to environment. This is an observational cross-sectional study, developed with $35 \mathrm{NB}$ admitted in a Maternity Hospital in Maceio-AL, from April to June 2009, which was used direct observation together film. Signs of approximation in the subsystems were observed, concluding that the humanized bath favors self-organization of these NB.
\end{abstract}

KEY WORDS: Infant, premature. Infnat, low birth weight. Humanization of assistance. Crosssectional studies.

\title{
REFERÊNCIAS
}

BRASIL. Ministério da Saúde. Norma de atenção humanizada do recém-nascido de baixo peso - método canguru. Brasília, 1999. 64p. Disponível em: http://www.portalhumaniza.org.br/ph/texto. asp?id=58>. Acesso em: 01 mai. 2008.

BRASIL. Ministério da Saúde. Atenção humanizada ao recémnascido de baixo peso - método Mãe Canguru: manual do curso. Brasília, 2002. Disponível em: http://www.fiocruz.br/redeblh/ media/manualcanguru.pdf . Acesso em: 01 mai. 2008.

BRASIL. Ministério da Saúde. Atenção humanizada ao recémnascido de baixo peso - método Mãe Canguru: normas e manuais técnicos. Brasília, 2009. Disponível em: http://www.aleitamento. com $/$ a artigos. asp id $=4 \&$ id $\operatorname{artigo}=2039 \&$ id subcategoria $=5$. Acesso em: 25 jul. 2009.

CARDOSO, A. C. A.; ROMITI, R.; RAMOS, J. L. A.; ISSLER, H.; GRASSIOTTO, C.; SANCHES, M. T. C. Método MãeCanguru: aspectos atuais. Rev. Pediatr., São Paulo, v. 28, n. 2, p. 128-134, 2006.

CARDOSO, M. V. L. M. L.; ROLIM, K. M. C.; FONTENELE, F. C.; GURGEL, E. P. P.;COSTA, L. R. Respostas fisiológicas e comportamentais do recém-nascido de risco durante o cuidado da enfermeira. Rev. Gaúcha Enferm., São Paulo, v. 28, n. 1, p. 98-105, 2007.

CARVALHO, M. R.; PROCHNIK, M. Método Mãe-Canguru de atenção ao prematuro, n. 1, Rio de Janeiro: BNDES, 2001.

COLE, M.; COLE, S. R. Desenvolvimento pré-natal e nascimento. In: COLE, M.; COLE, S. R. O desenvolvimento da criança e do adolescente. 4a. ed., Porto Alegre: Ed. Artmed, 2003. p. 100-141.

CONCEIÇÃO, J. A. N.; HAYASHI, A.; QUARENTEI, G.; ALCANTARA, P.de. Higiene Física. In: MARCONDES, E.; VAZ, F. A. C.; RAMOS, J. L. A.; OKAY, Y. Pediatria básica: pediatria geral e neonatal. 9a. ed. São Paulo: Sarvier, 2002. p. 113-117.

CUNHA, M. L. C.; MENDES, E. N. W.; BONILHA, A. L. L. O cuidado com a pele do recém-nascido. Rev. Gaúcha Enferm., Porto Alegre, v.23, n. 2, p. 6-15, jul. 2002. Disponível em: http://www. seer.ufrgs.br/index.php/RevistaGauchadeEnfermagem/article/ viewArticle/4444. Acesso em: 04 mai. 2008.

HENNINGSSON, A.; NYSTRÖM, B.; TUNNELL, R. Bathing or washing babies after birth? Lancet, v.2, n. 8260/8261, p.14011403, 1981.

LEONE, C. R.; RAMOS, J. L. A.; VAZ, F. A. O recém-nascido pré-termo. In: MARCONDES, E.; VAZ, F. A. C.; RAMOS, J. L. A.; OKAY, Y. Pediatria básica: pediatria geral e neonatal. 9a. ed. São Paulo: Sarvier, 2002. p. 348-352.

MEYERHOF, P. G. Qualidade de vida: estudo de uma intervenção em unidade de terapia neonatal de recém-nascidos pré-termo. 1996. 208 f. Tese (Doutorado em Ciências - área de concentração: Psicologia Experimental) - Instituto de Psicologia, Universidade de São Paulo, São Paulo.

MILTERSTEINER, A. R.; MILTERSTEINER, D. R.; RECH, V. V.; MOLLE, L. D. Respostas fisiológicas da posição Mãe-Canguru em bebês pré-termos, de baixo peso e ventilado espontaneamente. Rev. Bras.de Saúde Materno-Infantil, Recife, v. 3, n. 4, out./dez. 2003.

MURAHOVSCHI, J. Pediatria: diagnóstico + tratamento. 6a. ed. São Paulo: Sarvier, 2006.

NICOLAU, C. M.; MODESTO, K.; NUNES, P.; ARAÚJO, K.; AMARAL, H.; FALCÃO, M. C. Avaliação da dor no recém-nascido prematuro: parâmetros fisiológicos versus comportamentais. Arq.Bras. Ciênc. Saúde, Santo Andre, v. 33, n. 3, p. 146-150, 2008. Disponível em: http://bases.bireme.br/cgi-bin/wxislind.exe/iah/ online/?IsisScript=iah/iah.xis\&src=google \&base=LILACS\&lan 
$\mathrm{g}=\mathrm{p} \&$ nextAction $=$ lnk\& exprSearch=501339\&indexSearch $=$ ID. Acesso em: 14 jul. 2008.

REGO, M. A. S.; TAVARES, E. C.; MEGALE, L.; LEÃO, E. Assistência ao recém-nascido. In: CORRÊA, M. D.; MELO, V. H.; AGUIAR, R. A. L. P. Noções Práticas de Obstetrícia, 13. ed., Belo Horizonte: Ed. Médica Coopmed, 2004, p. 827-845.

RIBEIRO, M.A.C. CALDERON, L.A.; GARCIA, M. H. C. Aspectos que influenciam a termorregulação: assistência de enfermagem ao recém-nascido pré-termo. 2005. 48 f. Trabalho de Conclusão de
Curso (Bacharelado em Enfermagem) - Faculdade JK, Taguatinga, DF, 2005. Disponível em: www.paulomargotto.com.br/documentos/termorregulacao.doc. Acesso em: 04 mai. 2008.

STOLL, B. J.; KLIEGMAN, R. M. O recém-nascido. In: BEHRMAN, R. E.; KLIEGMAN, R. M.; JENSON, H. B. Nelson: tratado de pediatria. 16a. ed. Rio de Janeiro: Guanabara Koogan, 2002. p. 449-481;

TAMEZ, R. N. Intervenções no cuidado neuropsicomotor do prematuro: UTI neonatal. Rio de Janeiro: Guanabara Koogan, 2009. 